\title{
Jeca Tatu, um ilustre opilado: 0 movimento sanitarista e o combate à anciolostomíase na obra de Monteiro Lobato (Brasil, décadas de 1910-1920)
}

Jeca Tatu, a notable hookworm patient: the sanitary movement and the fight against hookworm disease in the work of Monteiro Lobato (Brazil, decades of 1910-1920)

Jeca Tatu, un ilustre opilado: el movimiento sanitarista y el combate a la anquilostomiasis en la obra de Monteiro Lobato (Brasil, décadas de 1910-1920)

Ana Paula Korndörfer

\section{Resumo}

Ao longo da década de 1910, iniciou-se uma campanha pela reforma da saúde e pelo saneamento rural no Brasil. Uma das principais bandeiras dessa campanha era o combate às endemias rurais, como a ancilostomíase. Em um contexto de estreita relação entre o campo literário e a área médica, nossa proposta, neste artigo, é recuperar parte da discussão que aborda os reflexos dos argumentos e das propostas dos defensores do movimento sanitarista sobre a obra do escritor Monteiro Lobato, enfocando, no entanto, o combate à ancilostomíase, a partir de uma breve discussão da trajetória de Jeca Tatu, um de seus mais conhecidos personagens.

Palavras-chave: Ancilostomíase. Monteiro Lobato. Movimento sanitarista.
Ao longo da década de 1910, iniciou-se uma campanha pela reforma da saúde e pelo saneamento rural no Brasil. Este período, momento em que se intensificam os debates sobre saúde e saneamento no país, é marcado pelo surgimento, no Brasil e no exterior, de movimentos de caráter nacionalista. De acordo com Nísia Trindade Lima e Gilberto Hochman,

Doutora em História pela Pontifícia Universidade Católica do Rio Grande do Sul. Professora Assistente I no Programa de Pós-Graduação em História da Universidade do Vale do Rio dos Sinos. E-mail: aninha.korndorfer@gmail.com

Recebido em 10/4/2018 - Aprovado em 20/5/2018 http://dx.doi.org/10.5335/hdtv.18n.3.8599 
[...] o período correspondente à Primeira Guerra Mundial e ao imediato pós-guerra foi, no exterior e no Brasil, marcado por uma intensa atuação de movimentos nacionalistas, que pretendiam descobrir, afirmar e reclamar os princípios da nacionalidade e realizá-los por intermédio do Estado (LIMA; HOCHMAN, 2004, p. 497).

Quatro eventos são apontados como significativos e fundadores do movimento sanitarista brasileiro: (1) o discurso de Miguel Pereira, professor da Faculdade de Medicina do Rio de Janeiro, em 1916, caracterizando o país como um imenso hospital; (2) o impacto causado pela publicação, também em 1916, do relatório da expedição médico-científica do Instituto Oswaldo Cruz ao interior, em 1912; (3) a fundação da Liga Pró-Saneamento do Brasil, em 1918; e (4) a repercussão dos artigos escritos por Belisário Penna sobre saúde e saneamento e reunidos em publicação, em 1918, sob o título Saneamento do Brasil (LIMA; HOCHMAN, 2004, p. 498-499 e LIMA, 1999, p. 105-107). ${ }^{1}$

O discurso de Miguel Pereira, professor da Faculdade de Medicina do Rio de Janeiro (FMRJ) e presidente da Academia Nacional de Medicina (ANM), era uma saudação ao diretor da FMRJ, o professor Aloysio de Castro. Segundo Gilberto Hochman, o discurso foi proferido no contexto de um debate de cunho nacionalista que girava em torno do recrutamento e do serviço militar obrigatórios (HOCHMAN, 1998, p. 65). As palavras de Miguel Pereira eram uma crítica ao desconhecimento - ingenuidade e ignorância - do deputado federal mineiro Carlos Peixoto com relação ao Brasil e seus habitantes caboclos e sertanejos, vistos, muitas vezes, sob uma ótica romântico-ufanista. O Brasil, no discurso de Miguel Pereira, era ainda um imenso hospital, pois parte ponderável de sua população se constituiria de doentes, famintos e ignorantes, gente esquecida pelo Estado.

O impacto das palavras de Miguel Pereira transformou seu discurso, em 1916, no ato fundador do movimento pelo saneamento do Brasil,

[...] um amplo movimento de opinião pública que diagnosticava a doença como o principal problema nacional, e o descaso das elites, a razão pela qual pouco se fizera para solucioná-lo (HOCHMAN, 1998, p. 66).

O discurso de Pereira foi inspirado no relatório, divulgado também em 1916, da expedição científica organizada pelo Instituto Oswaldo Cruz, em 1912, e chefiada por Belisário Penna e Arthur Neiva. Esta foi uma das três expedições científicas do Instituto Oswaldo Cruz enviadas ao Nordeste, em 1912, a serviço da Inspetoria das Obras contra a Seca, para realizar um "amplo levantamento das condições de saúde das populações do sertão" (THIELEN et al., 2002, p. 55). ${ }^{2}$ Entre 17 de abril e 17 de julho de 1912, a expedição chefiada por Adolpho Lutz e Astrogildo Machado percorreu o vale do São Francisco. João Pedro de Albuquerque e José Gomes de Faria atravessaram os estados do Ceará e do Piauí entre março e julho de 1912. Belisário Penna e Arthur Neiva percorreram aproximadamente sete mil quilômetros entre março e outubro de 1912, passando pelo norte da Bahia e pelos estados do Piauí e de Goiás. A expedição de Penna e Neiva destaca-se, entre as três, pela riqueza das observações de caráter sociológico e antropológico que apresentaram em seu relatório de viagem, bem como pelos seus numerosos registros fotográficos (THIELEN et al., 2002). 
O relatório produzido por Penna e Neiva a partir desta expedição continha informações climáticas, geográficas, socioeconômicas e nosológicas da extensa área percorrida, além de sugestões às autoridades públicas. O retrato do Brasil esboçado através do relatório apontava a doença e o abandono, e não o clima ou a raça, como principais problemas para o progresso das regiões percorridas.

Fazendo uma avaliação sobre a importância do relatório de Belisário Penna e Arthur Neiva no contexto do movimento sanitarista brasileiro, Hochman afirma que este

[...] foi peça fundamental para um diagnóstico, ou melhor, para uma redescoberta do Brasil, que mobilizou intelectuais e políticos, e impulsionou a campanha pelo saneamento. Além disso, o retrato do país apresentado nesse documento foi comentado e reproduzido em jornais e em debates acadêmicos e parlamentares, tendo convencido e convertido parte da opinião pública ao seu cruel diagnóstico (1998, p. 66, grifo do autor).

Em 11 de fevereiro de 1918, foi criada a Liga Pró-Saneamento do Brasil, liderada por Belisário Penna ${ }^{3}$. O objetivo primeiro da Liga era, segundo Lima e Hochman (2004, p. 498) alertar as elites políticas e intelectuais para as precárias condições sanitárias do país, buscando apoio para uma ação pública efetiva de saneamento no interior. Lina Faria afirma que o movimento pela reforma sanitária, comandado pela Liga durante dois anos (1918-1920), “[...] constituiu umas das vias mais significativas para o projeto de construção da Nação. A idéia da saúde surgia claramente como fator de progresso" (CASTRO SANTOS; FARIA, 2003, p. 45-46, grifos do autor).

Além de divulgar o quadro sanitário do Brasil, os integrantes da Liga procura- vam, principalmente, pressionar o Poder Legislativo para que produzisse uma legislação sanitária e levasse a autoridade pública a assumir mais a responsabilidade no que se referia à saúde da população (HOCHMAN, 1998, p. 77). ${ }^{4}$

O médico Belisário Penna, líder da Liga Pró-Saneamento, foi um grande divulgador do diagnóstico sobre as péssimas condições de saúde da população brasileira no período, aproveitando todas as oportunidades que lhe foram dadas para expressar publicamente seus argumentos em prol do movimento sanitarista. A obra Saneamento do Brasil, publicada em 1918 e republicada em 1923, reunia trabalhos divulgados no periódico Correio da Manhã, além de expor o programa da Liga. Neste livro, Penna propunha, segundo Hochman

[...] uma interpretação das relações entre doença, sociedade e política, no Brasil, e a modificação do papel do Governo federal nos campos do saneamento e saúde pública. Tudo isso, a partir de uma crítica contundente ao federalismo e ao descaso das elites governantes (1998, p. 72).

O movimento sanitarista atribuiu grande importância às endemias rurais. ${ }^{5}$ A ancilostomíase ${ }^{6}$, verminose importante, como veremos, na discussão aqui proposta, a malária e a doença de Chagas eram consideradas a "trindade maldita" e deveriam ser "o foco principal" da ação estatal. Estes males "evitáveis", causados pelo abandono em que viviam grandes parcelas da população do país, explicariam a improdutividade do brasileiro, que, combalido pela doença, usufruiria de apenas um terço de sua capacidade produtiva, conforme cálculos de Belisário Penna (HOCHMAN, 1998). Sobre este tema, cabe alguma discussão. 
Como afirmamos anteriormente, o período em questão é marcado pelo surgimento, no Brasil e em outros países, de movimentos de caráter nacionalista. Lina Faria (2007, p. 51) afirma que a representação dos brasileiros, durante o século XIX e início do $X X$, era, segundo algumas correntes de interpretação, a de "degenerados, tanto moral, quanto racialmente". Segundo a autora, "a relação entre miscigenação, sífilis e degeneração estava presente no diálogo de cientistas, médicos e intelectuais e, de modo geral, nas elites brasileiras". A fisioterapeuta ainda reitera que uma das consequências dessa visão "racializada" foi o aprofundamento do estado de precariedade em que viviam as populações pobres do interior do Brasil:

[...] se a explicação da pobreza e da doença era racial, então pouco se podia esperar das elites brasileiras para corrigir os níveis de vida tão precários em que haviam mergulhado aquelas populações (FARIA, 2007, p. 52).

No século XX, ainda segundo a autora, os debates sobre o nacionalismo tornaram a realização da reforma sanitária em objetivo de luta de setores da sociedade. Para algumas correntes nacionalistas, "[...] um projeto de construção da Nação só seria viável por meio da integração do sertanejo à civilização do litoral" (FARIA, 2007, p. 52). Desta maneira, em lugar de atribuir à miscigenação, por exemplo, a decadência física e moral dos brasileiros, esta decadência passou a ser atribuí$\mathrm{da}$, por algumas correntes de pensamento, a fatores como a subnutrição, a ignorância, a pobreza, a herança escravista, entre outros (FARIA, 2007, p. 52). ${ }^{7}$ Para os defensores do movimento sanitarista, era possível, com os recursos da ciência, encontrar um caminho para os dilemas da nacionalidade brasileira, entendida como fragilizada pela doença.
As propostas e os argumentos dos defensores da campanha pelo saneamento rural ganharam diversos espaços na sociedade brasileira: jornais, periódicos médicos, fóruns profissionais, organizações de classe e o Congresso Nacional. Ao longo do tempo, afirma Hochman

[...] foi se constituindo uma rede de indivíduos, instituições e órgãos públicos que compartilhavam uma interpretação geral sobre a centralidade da doença e das endemias rurais na compreensão dos problemas do país (1998, p. 111).

E esta rede não era formada apenas por agentes relacionados ao campo da medicina, mas também por políticos e profissionais de outras áreas, como engenheiros, jornalistas e escritores, como Monteiro Lobato, por exemplo, que, "convertido", tornou-se grande divulgador das ideias de saneamento.

Ilana Löwy, ao abordar a participação de escritores como Monteiro Lobato no movimento sanitarista brasileiro da segunda metade de década de 1910, afirma que esta

[...] reflete uma convergência entre discurso médico e discurso artístico no Brasil durante as primeiras décadas do século $X X$. Os intelectuais brasileiros procuraram desenvolver um discurso identitário apoiado simultaneamente na ciência, especialmente na biologia e na medicina (que vai explicar a 'verdadeira natureza do Brasil') e na literatura que, por meios muito diferentes, também pode exprimir as verdades essenciais do país. As duas verdades foram vistas como complementares. Cientistas, tais como os médicos Afrânio Peixoto, Miguel Couto e Oswaldo Cruz, foram eleitos membros da Academia Brasileira de Letras, enquanto um dos autores mais venerados da época, Euclides da Cunha, é engenheiro (2006, p. 107). 
Ainda segundo a autora, intelectuais rejeitaram a noção da 'arte pela arte' e afirmaram a importância da inserção da literatura na sociedade de seu tempo. Nas primeiras décadas do século $X X$, há, no país, uma estreita relação entre o campo literário e a área médica:

[...] a literatura e a medicina tornaram-se os veículos dos problemas nacionais, e ambos tentaram encontrar 'remédios' para os 'males' do país, e meios de curar 'um organismo social doente' (LÖWY, 2006, p. 107). ${ }^{8}$

Lobato, segundo Ilana Löwy (2006, p. 107), era o "mais marcante dos militantes diretamente engajados na luta pelo 'saneamento do país'".

José Bento Monteiro Lobato (18821948) nasceu em Taubaté (São Paulo), filho de José Bento Marcondes Lobato e de Olímpia Monteiro Lobato. A família do pai de Lobato possuía grandes fazendas de café no vale do rio Paraíba, e seu avô materno, José Francisco Monteiro, visconde de Tremembé, também era um rico proprietário de terras.

Monteiro Lobato cursou o primário e o ginásio em Taubaté, nos Colégios Paulista e Coração de Jesus. Em 1896, transferiu-se para a capital paulista, concluindo seus estudos preparatórios no Instituto de Ciências e Letras. Com o falecimento de seus pais (o pai de Lobato faleceu em 1898 e sua mãe, no ano seguinte), Lobato passou a viver com seu avô materno, que o induziu a matricular-se na Faculdade de Direito de São Paulo em 1900.

Desde o ginásio, Lobato já se dedicava a publicações em jornais e outras atividades literárias. Em 1904, formado, Lobato voltou para Taubaté. Em 1906, começou a trabalhar como procurador público da cidade e, em 1907, foi efetivado na promotoria de Areias, São Paulo. No ano seguinte, 1908, Lobato casou-se com Maria Pureza Natividade, com quem teve quatro filhos. Lobato colaborava com diversos jornais e trabalhava também como tradutor. Em 1911, com a morte do avô, Lobato herdou a fazenda Buquira e, mudando-se para a propriedade, trabalhou como administrador, empreendimento que fracassou.

Em 1914, Lobato publicou um artigo em $O$ Estado de São Paulo sobre a sua experiência como administrador da fazenda e caracterizou os caboclos como indolentes, preguiçosos e ignorantes. $\mathrm{O}$ artigo intitulava-se Velha Praga. ${ }^{9}$ Lobato vendeu a propriedade em 1917 e continuou a escrever para o jornal paulista e para outros periódicos. Em dezembro de 1914, publicou Urupês e, em 1915, comprou a Revista do Brasil. Em 1918, o autor publicou Problema Vital. No mesmo ano, Lobato fundou a Editora Monteiro Lobato, fechada, por problemas econômicos, em 1925.

Com os recursos que lhe restaram, Lobato associou-se a outros na fundação da Companhia Editora Nacional. Na mesma época, candidatou-se a uma vaga na Academia Nacional de Letras, mas foi derrotado.

Em 1927, na presidência de Washington Luís, foi nomeado adido comercial do Brasil em Nova York. Deslumbrado com o progresso e a economia (especialmente a siderurgia e a indústria petrolífera) norte-americanos, Lobato vendeu suas ações da Companhia Editora Nacional e investiu na bolsa de Nova York, perdendo todo o seu capital em 1929. Voltando ao Brasil em 1931, o escritor atraiu a atenção do governo 
brasileiro para o problema siderúrgico e petrolífero, mas sem sucesso. Buscando apoio de empresários, Lobato fundou o Sindicato Nacional de Indústria e Comércio e a Companhia Petróleos do Brasil. Lobato investiu em petróleo e debateu sua importância para a economia do Brasil, mas suas atividades como empresário não renderam lucros.

Na década de 1930, Lobato escrevia e traduzia para sobreviver e envolvia-se em polêmicas relacionadas à exploração do petróleo no país, que levaram à sua prisão em 1941. Na década de 1940, participou da fundação, juntamente com Arthur Neiva e Caio Prado Júnior, da Editora Brasiliense. Após decepções políticas com o comunismo, o escritor viajou para a Argentina e fundou a Editora Acteon. Em 1948, Lobato voltou ao Brasil e reaproximou-se do comunismo. Monteiro Lobato faleceu em São Paulo naquele mesmo ano. ${ }^{10}$

Da vasta produção literária de Monteiro Lobato, gostaríamos de destacar duas publicações acima mencionadas: Urupês e Problema Vital. Nessas duas obras, podemos observar as "[...] mudanças verificadas na compreensão do escritor paulista sobre o que acreditava ser os males do Brasil", pela trajetória de seu personagem Jeca Tatu (LIMA; HOCHMAN, 2004, p. 509). Como veremos, a tomada de consciência da gravidade dos efeitos, no Brasil, de doenças como a ancilostomíase teve parte nessas mudanças verificadas na compreensão de Lobato sobre quais seriam os problemas nacionais.

Em Urupês, conto publicado em $O$ Estado de São Paulo em 1914, Monteiro Lobato caracterizava o habitante das zonas rurais do Brasil, representado pelo caipira do vale do Paraíba de nome Jeca Tatu, como sendo indolente, imprevidente, parasita, sujo e burro (LOBATO, 2010, p. 166-177; LIMA; HOCHMAN, 2004，p. 510; LÖWY, 2006, p. 143). ${ }^{11}$

O caipira brasileiro apresentado por Lobato em Urupês não produzia, servia-se do que a natureza lhe dava; era seguidor da lei do menor esforço; morava numa casa de sapé e lama que fazia "gargalhar ao joão-de-barro"; não utilizava mobília, talheres ou roupas; não possuía senso estético; era um nômade sem sentimentos patrióticos que buscava em mezinhas, curadores, simpatias e crendices as soluções para os seus problemas de saúde. O Jeca, bonito no romance e feio na realidade, era "maravilhoso epítome onde se resumem todas as características da espécie" (2010, p. 169).

Para Monteiro Lobato, os brasileiros dos agrestes e das matas do país em nada se pareciam aos personagens do indianismo ou do "caboclismo". O caboclo vegetava de cócoras, incapaz de evolução, impenetrável ao progresso. Feio e sorno, nada colocava o caboclo de pé:

Quando Pedro I lança aos ecos o seu grito histórico e o país desperta estrouvinhado à crise duma mudança de dono, o caboclo ergue-se, espia e acocora-se de novo.

Pelo 13 de Maio, mal esvoaça o florido decreto da Princesa e o negro exausto larga num uf! o cabo da enxada, o caboclo olha, coça a cabeça, imagina e deixa que do velho mundo venha quem nele pegue de novo.

Em 15 de Novembro troca-se o trono vitalício pela cadeira quadrienal. O país bestifica-se ante o inopinado da mudança, o caboclo não dá pela coisa (LOBATO, 2010, p. 169, grifos do autor). 
Segundo Éder Silveira, Urupês logo se tornou conhecida pelo retrato impiedoso que fazia do caipira, pela imagem crua que construía das populações rurais: "Lobato expressa a descrença de que em um país repleto de Jecas pudesse ser imaginado o progresso e a civilização" (2005, p. 189). Para Lobato, ainda segundo o autor, a raça e o meio eram os condicionantes para que o homem do interior do Brasil fosse assim (SILVEIRA, 2005, p. 191). ${ }^{12}$

Mas essa visão de Lobato sobre os habitantes do interior se modifica quando ele toma conhecimento dos relatórios, já mencionados, das viagens de cientistas do Instituto Oswaldo Cruz, como Belisário Penna e Arthur Neiva, ao interior do país. A partir de então, o escritor percebe que o Jeca Tatu estava, na verdade, doente. O Jeca sofria com uma das doenças que compunham a "trindade maldita", a ancilostomíase (LÖWY, 2006, p. 143).

O combate à verminose, também conhecida como opilação e mal da terra ${ }^{13}$, foi, como já indicamos, uma das bandeiras do movimento pelo saneamento rural no Brasil. No contexto do movimento sanitarista, a doença tornou-se o símbolo da apatia do trabalhador rural e do descaso das elites políticas diante dos problemas do país.

O médico sanitarista Belisário Penna afirmava que a doença atingia $70 \%$ da população rural do país no período e deveria ser "o primeiro alvo de uma campanha nacional de saneamento e educação higiênica" (HOCHMAN, 1998, p. 74-75).

Penna afirmava, sobre a ancilostomíase, que
É uma doença que enfraquece o corpo, abate a intelligencia, produz a preguiça e o desanimo, envenena e destroe o sangue, e faz a desgraça de milhões de brasileiros. É uma doença que mata, todos os annos, milhares de crianças patricias; que definha e prejudica o desenvolvimento do corpo e da intelligencia de dezenas de milhares de outras, que escapam á morte; que reduz de mais de metade a capacidade de trabalho de milhares de homens, que, por isso, vegetam na miseria e viciam-se na cachaça; que é a causa de muitas ulceras e feridas rebeldes, e de muitas doenças chronicas do coração, dos rins, do figado, do estomago e dos intestinos, que matam annualmente milhares de pessoas. $\mathrm{O}$ amarellão constitue a maior calamidade do Brasil. Enquanto não for dado combate decisivo a esse mal não conseguirá o paíz prosperar na proporção das suas riquezas naturaes e das modernas conquistas da sciencia (1928, p. 54).

Não tendo o apelo causado por uma epidemia como a de febre amarela, por exemplo, a ancilostomíase não recebia, na opinião de Penna, a atenção necessária. A permanência da doença, endemicamente, levava ao enfraquecimento do brasileiro, que se tornava mais suscetível a outras doenças. Tornado improdutivo pela ação de doenças "evitáveis", o trabalhador nacional representava entraves ao progresso e ao desenvolvimento econômico do país (HOCHMAN, 1998, p. 75).

Após ter contato com as ideias e propostas dos defensores da campanha pelo saneamento rural, Lobato passa a defender a ideia de que o caipira indolente, imprevidente e parasita poderia transformar-se e tornar-se "um agente de mudança social e modernização" (LIMA; HOCHMAN, 2004, p. 511). Como afirma Nísia Trindade Lima: 
[...] o diagnóstico sobre a preguiça do caboclo mudara; às doenças, reveladas à nação por meio dos relatórios das viagens dos cientistas do Instituto Oswaldo Cruz ao interior, cabia a responsabilidade pela situação de miséria e indigência em que se encontrava o caboclo (1999, p. 146).

Em 1918, mesmo ano em que Belisário Penna lançou Saneamento do Brasil, Lobato publica Problema Vital, uma coletânea de artigos sobre saneamento divulgados no jornal O Estado de São Paulo e editado, entre outros, pela Liga Pró-Saneamento.

Recorrendo novamente a Silveira, o autor afirma que

Com a publicação de Problema Vital, obra que reúne seus ensaios jornalísticos, todos eles versando sobre higienismo e eugenia ${ }^{14}$, Monteiro Lobato concretiza sua postura de intelectual engajado no movimento sanitarista. Problema Vital rapidamente tornou-se um manifesto em prol da ação da intelligentsia brasileira, que, ao seu ver, deveria voltar o olhar aos problemas nacionais (SILVEIRA, 2005, p. 192. Grifos do autor).

Em Problema Vital, Monteiro Lobato dedicou algumas páginas às doenças que compunham a "trindade infernal" ou "trindade maldita": o Brasil possuía 17 milhões de opilados (ancilostomíase), três milhões de idiotas (doença de Chagas) e 10 milhões de impaludados (malária), numa população composta por aproximadamente 25 milhões de habitantes (LOBATO, 1959, p. 231-252).

A ancilostomíase, doença causada por "horrendos vermes" que se "aboletavam no duodeno do homem como em sua casa", trazia diversos males ao homem, segundo Lobato, sendo responsável por anemia, baixa do tônus vital, enfraquecimento da defesa natural do organismo e, ainda por cima, inclinava o opilado ao vício da cachaça, "[...] lenitivo a que recorre para contrabater a permanente sensação de frio que o desequilibrio sanguineo acarreta". Além disso, a ancilostomíase causava o atrofiamento da inteligência do "amarelado", que se tornava "um soturno urupê humano, incapaz de ação, incapaz de vontade, incapaz de progresso" (1959, p. 233).

Para Lobato, os heroicos sertanejos, fortes e generosos, e as caipirinhas com faces cor de jambo ainda não passavam de "licenças bucólicas de poetas jamais saídos das cidades grandes", mas assim o eram por causa da doença, miséria fisiológica responsável pela miséria econômica do país (LOBATO, 1959 , p. 234). Segundo o escritor,

O que nos campos a gente vê, deambulando pelas estradas com ar abobado, é um lamentavel naufrago da fisiologia, a que chamamos homem por escassez de sinonimia. Feiíssimo, torto, amarelo, cansado, exangue, faminto, fatalista, geofago - viveiro ambulante do verme destruidor.

Do lado feminino é a mulher sem idade, macilenta aos doze anos, velha aos dezesseis, engrouvinhada aos vinte, mumia aos trinta, e como o homem, ocupada na tarefa de abrigar carinhosamente no seio a fauna infernal (LOBATO, 1959, p. 234).

O grave problema, entretanto, tinha solução: defender os pés com o uso de calçados e evitar a infecção com o uso da fossa sanitária. A tarefa, a princípio simples, segundo Lobato, era facílima e dificílima ao mesmo tempo. Entre as dificuldades para o combate à ancilostomíase, Lobato destacava o desinteresse dos governos brasileiros em estudar e buscar soluções para "problemas internos", como a doença. Curar e sanear o 
Brasil eram tarefa de governos e particulares. Não era a raça que explicava os problemas nacionais, e, sim, "[...] o longo e ininterrupto estado de doença transmitido de pais a filhos e agravado dia a dia" (LOBATO, 1959, p. 306).

Mas o saneamento do Brasil, apesar das dificuldades e dos obstáculos, traria infindáveis benefícios ao Brasil. Em Problema Vital, o Jeca Tatu de Lobato, antes desanimado, preguiçoso, bêbado e idiota, transforma-se ao acreditar na ciência e ao seguir as suas prescrições. Diagnosticado e curado da ancilostomíase, e assim livre do cansaço e do desânimo, Jeca Tatu passa a ser um trabalhador produtivo, incansável e valente e, pouco depois, torna-se um próspero fazendeiro, com uma propriedade moderna, novas lavouras e tecnologias. O Jeca agora sabia falar inglês, possuía automóvel e telefone. Em competição com um vizinho italiano, Jeca Tatu ultrapassa-o e vence. Mas, além de próspero fazendeiro, Jeca Tatu transforma-se também em educador sanitário, transmitindo o que aprendera aos empregados de sua propriedade. Rico e estimado, Jeca resolveu "ensinar o caminho da saúde aos caipiras das redondezas" e abriu postos de combate à ancilostomíase. Morrendo aos 89 anos, o personagem de Lobato tinha a satisfação de ter cumprido sua missão (LIMA; HOCHMAN, 2004, p. 511; LÖWY, 2006, p. 143-144; LIMA, 1999, p. 147).

Ao regenerar seu personagem, afirmando que o Jeca era um brasileiro doente e não um degenerado, Lobato operou um "importante deslocamento conceitual". Para Éder Silveira,
[...] passa a ser transitório o estado de apatia em que o Jeca se encontra. Assim, era possível, segundo parecer redentor da ciência, explorar de forma plena as potencialidades do contingente populacional brasileiro, pois a apatia, antes inata, agora era medicável (2005, p. 194).

No início dos anos 1920, Monteiro Lobato criou o Jeca Tatuzinho, personagem que retomava a defesa do saneamento rural e, adaptado pelo autor, foi propaganda de "preparados medicinais contra malária e opilação" do Laboratório Fontoura (GOMES, 2006, p. 1013). ${ }^{15}$

Como observamos, a ancilostomíase era a doença responsável pela apatia e improdutividade de Jeca Tatu, personagem que, transformado, passou a ser mais um meio de propaganda da campanha pelo saneamento rural do Brasil. Ao optar pela doença como uma das responsáveis pelos "males do Brasil", o escritor apostava também na possibilidade de sanar os problemas do país, fazendo eco às ideias defendidas por homens como Belisário Penna. ${ }^{16} \mathrm{~A}$ ancilostomíase, segundo Lobato, era "[...] praga tão grande que moveu a piedade de Rockefeller e o levou a organizar no mundo inteiro uma campanha contra [...]" (1959, p. 305) campanha esta, que chegaria ao Brasil ainda na década de $1910 .{ }^{17}$

As populações rurais passaram a ser incluídas nas políticas de saúde do governo federal, com destaque para a criação, em 1918, do Serviço de Profilaxia Rural e, em 1920, da Diretoria de Saneamento e Profilaxia Rural do Departamento Nacional de Saúde Pública - DNSP. A partir de 1918 e, principalmente, a partir de 1920, os estados passaram a contar com a possibilidade de solicitar o auxílio do governo federal para combater as endemias rurais com base em 
acordos de cooperação, mas que envolviam como contrapartida, entre outros aspectos, perda de autonomia por parte dos estados (HOCHMAN, 1998). Mas, além do governo federal, os estados puderam recorrer, a partir de 1916, a outro recurso para combater a ancilostomíase, a Fundação Rockefeller, instituição que já possuía experiência no combate à doença e que se inseria, assim, num contexto favorável a acordos para ações de saneamento e de combate a endemias rurais. Contaram com a cooperação da International Health Board ${ }^{18}$ da Fundação no combate à doença, entre 1916 e 1923, os estados do Rio de Janeiro, São Paulo, Minas Gerais, Paraná, Maranhão, Rio Grande do Sul, Espírito Santo, Bahia, Santa Catarina, Pernambuco e Alagoas, além do Distrito Federal (KORNDÖRFER, 2013).

\section{Abstract}

Throughout the decade of 1910, a campaign for health reform and rural sanitation began in Brazil. One of the main flags of the campaign was the fight against rural endemics, such as hookworm disease. In a context of close relationship between the literary and the medical fields, our proposal, in this article, is to recover part of the discussion that addresses the reflexes of the arguments and proposals of the defenders of the sanitary movement about the work of the writer Monteiro Lobato, focusing, however, on the fight against hookworm disease, from a brief discussion of the trajectory of Jeca Tatu, one of his best known characters.

Keywords: Hookworm disease. Monteiro Lobato. Sanitary movement.

\section{Resumen}

A lo largo de la década de 1910, se inició una campaña por la reforma de la salud y por el saneamiento rural en Brasil. Una de las principales banderas de esta campaña era el combate a las endemias rurales, como la anquilostomiasis. En un contexto de estrecha relación entre el campo literario y el área médica, nuestra propuesta, en este artículo, es recuperar parte de la discusión que aborda las reflexiones de los argumentos y propuestas de los defensores del movimiento sanitarista sobre la obra del escritor Monteiro Lobato enfocando el combate a la anquilostomiasis, a partir de una breve discusión de la trayectoria de Jeca Tatu, uno de sus más conocidos personajes.

Palabras clave: Anquilostomiasis. Monteiro Lobato. Movimiento sanitarista.

\section{Notas}

1 É válido destacar aqui que a publicação de $O s$ Sertões, de Euclides da Cunha, em 1902, é apontada por diversos autores como importante no processo de "descoberta" dos "sertões" brasileiros pelas elites do país (LÖWY, 2006; CASTRO SANTOS, 1985; LIMA, 1999). Cabe aqui uma observação sobre "os sertões", tão presentes nos textos sobre o movimento sanitarista. Nísia Trindade Lima e Gilberto Hochman esclarecem que "os sertões", no contexto da campanha pelo saneamento do Brasil, eram mais uma categoria social e política do que geográfica: "sua localização espacial dependeria da existência do binômio 'abandono e doença'. Na verdade, os sertões do Brasil não estariam tão longe assim daqueles a quem se demandavam medidas de saneamento, nem seriam apenas uma referência simbólica ou geográfica ao interior do país. Na instigante percepção de Afrânio Peixoto, os 'sertões do Brasil' começavam no fim da Avenida Central, o grande boulevard da então capital federal, a cidade do Rio de Janeiro" (LIMA; HOCHMAN, 2004, p. 502). 
2 A Inspetoria das Obras contra a Seca foi criada em 1900 e estava vinculada ao Ministério da Viação e Obras Públicas. Em fins de 1911, seus serviços estavam definitivamente organizados. Os objetivos da Inspetoria eram "[...] 'atender os desastrosos efeitos das secas periódicas que flagelam o Nordeste do Brasil, compreendendo o norte do Estado de Minas Gerais, áreas consideráveis da Bahia, Sergipe, Alagoas, Pernambuco, Paraíba e Piauí, e os estados do Rio Grande do Norte e do Ceará..."' (THIELEN et al., 2002, p. 53).

3 Belisário Augusto de Oliveira Penna (1868-1939) nasceu em Barbacena, Minas Gerais. Em 1886, matriculou-se na Faculdade de Medicina do Rio de Janeiro, mas concluiu o curso na Faculdade de Medicina da Bahia, em Salvador. Em 1918, Belisário Penna foi nomeado para o Serviço de Profilaxia Rural, criado pelo presidente Wenceslau Brás. Em 1920, quando foi criado o Departamento Nacional de Saúde Pública - DNSP - Penna instalou serviços de profilaxia rural em 15 estados durante a sua gestão. Exonerou-se do Departamento em 1922. Em 1933, assumiu interinamente o Ministério da Educação e Saúde Pública, solicitando sua aposentadoria naquele mesmo ano. $\mathrm{O}$ médico faleceu no interior do Rio de Janeiro em 1939 (THIELEN; SANTOS, 2002).

4 É importante observar que, a partir da proclamação da República, em 1889, as questões relativas à higiene e à saúde pública passaram a ser tratadas de forma descentralizada, obedecendo à Constituição de 1891, que estabelecia a autonomia dos estados. Encarregados dos serviços sanitários, os estados respondiam pela saúde pública e repassavam aos municípios as questões relativas à higiene. Apenas o Distrito Federal e a vigilância dos portos permaneceram sob responsabilidade do governo federal (HOCHMAN, 1998).

5 É cabido lembrar que o Brasil era um país predominantemente rural no período inicial da República. Boris Fausto afirma que, segundo o censo de 1920, "de 9,1 milhões de pessoas em atividade, 6,3 milhões $(69,7 \%)$ se dedicavam à agricultura, 1,2 milhão $(13,8 \%)$ à indústria e 1,5 milhão (16,5\%) aos serviços" (FAUSTO, 2001, p. 159).

6 A ancilostomíase ou ancilostomose é uma verminose adquirida, basicamente, através do contato da pele com o solo contaminado. Entre os sintomas da doença estão anemia, fraqueza e desânimo. O diagnóstico é realizado através da análise das fezes do paciente, pois os ovos dos ancilostomídeos são típicos e costumam ser abundantes na matéria fecal. É possível interromper a transmissão da ancilostomíase da seguinte maneira: (1) através do tratamento de indivíduos parasitados com anti-helmínticos, reduzindo ou suprimindo as fontes de infecção; (2) através de saneamento básico, com o uso de fossas sanitárias e latrinas ligadas a um sistema de esgoto, assegurando assim um destino adequado às fezes humanas $\mathrm{e}$ impedindo a contaminação do solo com os ovos e as larvas dos parasitas; (3) com o uso de calçados, protegendo, desta maneira, as pessoas contra a penetração das larvas infectantes (REY, 2001).

7 Diversos são os estudos que abordam as discussões no Brasil, a partir da segunda metade do século XIX, sobre o país e seus habitantes, as possibilidades de futuro para a Nação e seus impasses. Entre estes trabalhos, destacam-se o de Schwarcz (1993) e o de Mota (2000).

8 Abordando também a relação entre o campo literário e a área médica, Magali Engel afirma que o psiquiatra Afrânio Peixoto "[...] adentrou no mundo da produção literária construindo personagens e tramas profundamente impregnadas pelas crenças e preconceitos que caracterizavam o alienismo das primeiras décadas do século XX" (ENGEL, 2004, p. 337).

9 Segundo informações disponíveis no site de $O$ Estado de São Paulo, o texto intitulado Velha Pra$g a$ foi endereçado à Seção Queixas e Reclamações. $\mathrm{O}$ texto, que fazia duras críticas às queimadas realizadas pelos caboclos, foi considerado importante e acabou deslocado para o corpo do jornal, alcançando grande repercussão. Disponível em: <http://acervo.estadao.com.br/historia-do-grupo/decada_1910.shtm>. Acesso em: 02 ago. 2017.

10 As informações sobre Monteiro Lobato apresentadas aqui estão disponíveis em FERREIRA, Marieta de Moraes. LOBATO, Monteiro. In: Dicionário Histórico-Biográfico Brasileiro. Rio de Janeiro: FGV/CPDOC. Disponível em: <http:/ / www.fgv.br/cpdoc/acervo/dicionarios/verbete-biografico/jose-bento-monteiro-lobato>. Acesso em: 17 jan. 2017.

11 Sobre a representação dos tipos humanos das áreas rurais por viajantes, cronistas e escritores, ver Lima (1999, p. 134-138).

12 Segundo Nísia Trindade Lima, intensa polêmica sucedeu à publicação de Velha Praga e Urupês. Segundo Lima, periódicos questionavam a importância, a conveniência e a abrangência do caboclo acocorado e indolente retratado por Lobato (LIMA, 1999, p. 133).

13 Entre outras sinonímias da doença estão ainda cansaço, mal-coer, mal d'éstomac des nègres, anemia intestinal e geofagia (EDLER, 2011, p. 105).

14 Segundo Lilia Moritz Schwarcz, "o termo 'eugenia' - eu: boa; genus: geração - foi criado em 1883 pelo cientista britânico Francis Galton" (SCH- 
WARCZ, 1993, p. 60). Ainda segundo a autora, esta "espécie de prática avançada de darwinismo social" foi "transformada em um movimento científico e social vigoroso a partir dos anos de 1880" e cumpria metas diversas. "Como ciência, ela supunha uma nova compreensão das leis da hereditariedade humana, cuja aplicação visava a produção de 'nascimentos desejáveis e controlados'; enquanto movimento social, preocupava-se em promover casamentos entre determinados grupos e - talvez o mais importante - desencorajar certas uniões consideradas nocivas à sociedade" (SCHWARCZ, 1993, p. 60).

15 Em nota do texto Jéca Tatú - A Ressurreição, lemos: "Esta pequena historia teve um curioso destino. Adotada por Candido Fontoura, esse homem de visão tão penetrante, para propaganda de seus preparados medicinais contra a malaria e a opilação, vem sendo espalhada pelo país inteiro na maior abundancia. As tiragens já alcançaram quinze milhões de exemplares - e prosseguem. Não ha recanto do Brasil, não há fundo de sertão, onde quem sabe ler não haja lido o 'Jecatatuzinho', que é o nome popular da historia por causa do pequeno formato das edições distribuídas. $\mathrm{E}$ desta forma, graças á ação de Fontoura, as noções dadas no 'Jecatatuzinho' sobre as origens da malaria e da opilação já entraram no conhecimento do povo roceiro, habilitando milhares e milhares de criaturas a se defenderem e também a se curarem, quando por elas alcançados" (LOBATO, 1959, p. 340). Segundo Mario Luiz Gomes, "Monteiro Lobato foi o intelectual mais importante para a história da propaganda nos almanaques de farmácia. Amigo pessoal de Cândido Fontoura, foi o responsável pela idealização - e confecção - do exemplar inaugural (1920) do Almanach do Biotonico. Sua efetiva contribuição, porém, viria com a adaptação para a publicidade de seu controvertido personagem 'Jeca Tatuzinho'. Capitalizado para alavancar a campanha contra a verminose [...], foi lançado em livreto [...], transformando-se em sucesso imediato" (GOMES, 2006, p. 1013).

16 Nísia Trindade Lima destaca, porém, que “[...] em contraste com a ênfase de Belisário Penna, e de outros participantes da campanha de reforma da saúde pública, no saneamento dos sertões, Monteiro Lobato afirma que a idéia de sanear os sertões mais longínquos, quase desérticos, parecia pouco exeqüível e discutível do ponto de vista econômico, pois para tanto nem toda a fortuna de Rockefeller seria suficiente. [...] Monteiro Lobato nos fala de atribuir prioridade aos povoados, às vilas e às cidades do interior, impedindo sua estagnação" (LIMA, 1999, p. 149).

17 É interessante destacar que Alan Gregg, médico da Fundação Rockefeller que atuou nas atividades de combate à ancilostomíase no Brasil entre 1919 e 1922, referiu-se, em seu diário, em mais de uma oportunidade, à população tratada como sendo de "Jeca-Tatus", fornecendo indícios sobre o alcance do personagem de Monteiro Lobato como sinônimo, naquele momento, da população rural desassistida e doente (U.S. NATIONAL LIBRARY OF MEDICINE - Alan Gregg's Brazil diary, April 1919 - 21 November 1920 (MS C 190). Disponível em: <http://profiles.nlm.nih.gov/ ps/browse/ResourceResult/TYPE/Diaries/ CID/FS/sort/chron>. Acesso em: 20 nov. 2011).

18 A Divisão Internacional de Saúde da Fundação Rockefeller foi criada em 1913, ano em que foi criada a própria Fundação, e tinha como objetivo estender o trabalho de combate à ancilostomíase realizado pelos Rockefeller através da Sanitary Commission for the Eradication of Hookworm Disease nos Estados Unidos, desde 1909, para outros países. A Divisão chamou-se International Health Commission (IHC) entre 1913 e 1916, International Health Board (IHB) entre 1916 e 1927 e International Health Division (IHD) entre 1927 e 1951 e, ao encerrar as suas atividades em 1951, havia estado presente em mais de 80 países do mundo, incluindo todos os países da América do Sul (FARLEY, 2004, p. 2). As atividades de combate à ancilostomíase realizadas a partir de acordos de cooperação entre estados brasileiros e a Fundação Rockefeller foram discutidas em Korndörfer (2013).

\section{Referências}

CASTRO SANTOS, Luiz Antonio de; FARIA, Lina. A reforma sanitária no Brasil: ecos da Primeira República. Bragança Paulista: Edusf, 2003.

DICIONÁRIO HISTÓRICO-BIOGRÁFICO BRASILEIRO. Centro de Pesquisa e Documentação de História Contemporânea do Brasil. Fundação Getúlio Vargas. Disponível em: <http://www.fgv.br/cpdoc/acervo/dicionarios/verbete-biografico/jose-bento-monteiro-lobato>. Acesso em: 17 jan. 2017. 
EDLER, Flávio Coelho. A Medicina no Brasil Imperial: clima, parasitas e patologia tropical. Rio de Janeiro: Fiocruz, 2011.

ENGEL, Magali. Psiquiatria e feminilidade. In: PRIORE, Mary Del (Org.); BASSANEZI, Carla (Coord.). História das mulheres no Brasil. 7. ed. São Paulo: Contexto, 2004. p. 322-361.

FARIA, Lina. Saúde e Política: a Fundação Rockefeller e seus parceiros em São Paulo. Rio de Janeiro: Fiocruz, 2007.

FARLEY, John. To cast out disease: a history of the International Health Division of the Rockefeller Foundation (1913-1951). Nova York: Oxford University Press, 2004.

FAUSTO, Boris. História Concisa do Brasil. São Paulo: Editora da Universidade de São Paulo/ Imprensa Oficial do Estado, 2001.

GOMES, Mario Luiz. Vendendo saúde! Revisitando os antigos almanaques de farmácia. Rio de Janeiro, História, Ciências, Saúde, Manguinhos, v. 13, n. 4, p. 1007-1018, out./dez. 2006.

HOCHMAN, Gilberto. A era do saneamento: as bases da política de Saúde Pública no Brasil. São Paulo: Hucitec/ Anpocs, 1998.

KORNDÖRFER, Ana Paula. "An international problem of serious proportions": A cooperação entre a Fundação Rockefeller e o governo do estado do Rio Grande do Sul no combate à ancilostomíase e seus desdobramentos (19191929). Tese (Doutorado em História) - Programa de Pós-graduação em História, Pontifícia Universidade Católica do Rio Grande do Sul, Porto Alegre, 2013.

LIMA, Nísia Trindade; HOCHMAN, Gilberto. Pouca Saúde e Muita Saúva: sanitarismo, interpretações do país e ciências sociais. In: HOCHMAN, Gilberto; ARMUS, Diego (Org.). Cuidar, controlar, curar: ensaios históricos sobre saúde e doença na América Latina e Caribe. Rio de Janeiro: Fiocruz, 2004.
LOBATO, Monteiro. Mr. Slang e o Brasil e Problema Vital. 9. ed. São Paulo: Brasiliense, 1959. v. 8 .

LÖWY, Ilana. Virus, mosquitos e modernidade: a febre amarela no Brasil entre ciência e política. Rio de Janeiro: Fiocruz, 2006.

LOBATO, Monteiro. Urupês. 2. ed. São Paulo: Globo, 2010.

MOTA, Maria Aparecida Rezende. Sílvio Romero: dilemas e combates no Brasil da virada do século XX. Rio de Janeiro: FGV, 2000.

PENNA, Belisário. Amarellão e maleita. Rio de Janeiro: Benedicto de Souza, 1928.

REY, Luís. Um século de experiência no controle da ancilostomíase. Revista da Sociedade Brasileira de Medicina Tropical, v. 34, n. 1, p. 6167, jan./fev. 2001.

SANTOS, Ricardo Augusto dos. Belisário Penna: notas fotobiográficas. História, Ciências, Saúde, Manguinhos, v. 9, n. 2, p. 387-404, maio/ago. 2002.

SCHWARCZ, Lilia Moritz. O Espetáculo das Raças: cientistas, instituições e questão racial no Brasil - 1870-1930. 2. reimpr. São Paulo: Companhia das Letras, 1993.

SILVEIRA, Éder. Sanear para integrar: a cruzada higienista de Monteiro Lobato. Estudos Ibero-Americanos, v. 31, n. 1, p. 181-200, jun. 2005.

THIELEN, Eduardo Vilela et al. A ciência a caminho da roça: imagens das expedições científicas do Instituto Oswaldo Cruz ao interior do Brasil entre 1911 e 1913. 1. reimpr. Rio de Janeiro: Fiocruz / Casa de Oswaldo Cruz, 2002.

THIELEN, Eduardo Vilela; SANTOS, Ricardo Augusto dos. Belisário Penna: notas fotobiográficas. História, Ciências, Saúde, Manguinhos, v. 9, n. 2, p. 387-404, maio/ago. 2002. 